\title{
Modelling the Conditions Affecting Population Migration Activity in the Eastern European Region: The Case of Ukraine
}

\author{
Olha Levytska ${ }^{1}$, Olha Mulska ${ }^{1}$, Ulana Ivaniuk ${ }^{2}$, Marta Kunytska-Iliash ${ }^{3}$, \\ Taras Vasyltsiv ${ }^{1}$, Ruslan Lupak ${ }^{4}$
${ }^{I}$ M. Dolishniy Institute of Regional Research of National Academy of Sciences of Ukraine, Department of Social and Humanitarian Development of Regions, 4 Kozelnytska Str, 79026 Lviv, Ukraine
${ }^{2}$ Lviv Institute of Interregional Academy of Personnel Management, Department of Management of Organizations, 29 Hetmana Mazepy I. Str, 79059 Lviv, Ukraine
${ }^{3}$ Stepan Gzhytskyi National University of Veterinary Medicine and Biotechnologies of Lviv, Department of
Economics of Enterprise Innovations and Advisory in Agriculture named after Ivan Popovych, 50 Pekarska Str, 79010 Lviv, Ukraine
${ }^{4}$ Lviv University of Trade and Economics, Department of Economics, 10 Tuhan-Baranovskoho M. Str, 79008 Lviv, Ukraine

\begin{abstract}
This paper presents the authors' algorithm for estimating the conditions affecting population migration activity in the Eastern European region (on the example of Ukraine), which includes selection of indicators, determination of indicators' weights in a group, calculation of weighted multidimensional values by each group, determination of the weights of indicators' groups in the integral index, estimation of the calculation reliability, construction of the integral index and its interpretation. The concept of the conditions affecting migration activity is regarded as a set of factors distributed in five groups (demographic stability and public health status, education coverage, labour market and employment conditions, standard of living, country's economic development). Based on the results of estimating the conditions affecting population migration activity in Ukraine, the conclusions are drawn regarding the level of the country's enabling migration conditions.
\end{abstract}

DOI: $10.18421 /$ TEM92-12

https://doi.org/10.18421/TEM92-12

Corresponding author: Olha Levytska,

M. Dolishniy Institute of Regional Research of National

Academy of Sciences of Ukraine, Department of Social and Humanitarian Development of Regions, Lviv, Ukraine.

Email: o.levytska@gmail.com

Received: 27 January 2020.

Revised: 15 April 2020.

Accepted: 20 April 2020.

Published: 27 May 2020.

C2020 Olha Levytska at al; published by UIKTEN. This work is licensed under the Creative Commons Attribution-NonCommercial-NoDerivs 3.0 License. (c) BY-Nc-ND

The article is published with Open Access at www.temjournal.com
Keywords - conditions affecting migration, population migration activity, push factors, integral index, Ukraine.

\section{Introduction}

The research results concerning the demographic problems prove that modern tendencies, typical for the countries of Western and Central Europe, which among the first are connected with population aging, including the results of demographic changes in the characteristics of birth rate, death rate and, partially, migration, have led to increased demand for population reproduction in these countries, especially youth and people of working age [2], [11]. In the short-term period, one of the most efficient means to solve this problem is immigration, including labour immigration, from Ukraine as the region of Eastern Europe [13]. Forecasting, further planning of migration volumes and studying population activity are mainly based on the results of analysing migration environment factors [3], [5].

The developed set of factors affecting population migration is not systematic and complex enough. In numerous research papers, attention is focused on the issues of forced migration [1], human trafficking and workforce migration [8], short-term migration forms [9] and different aspects of the economy of labour migrants' employment [4], [10]. In the publications with reference to scientists studying migration, much attention is paid to socio-economic factors affecting migration processes in the countries and regions [6].

In recent decades, Europe has been experiencing cyclical fluctuations in the development, and migration has been economically profitable, as it is a way of solving the crisis of the replacement of lowpaid jobs. The econometric studies show that 
immigration to European countries targeted at recruitment is caused by disparities in national labour markets [14]. As a result, migrants are the source of changes in the society's development in different countries, and this cultural heritage is becoming of increasing interest to both researchers and migrant communities [7].

However, at present there is still no generally accepted methodology for assessing the conditions affecting population migration activity (with the full set of economic, political, social, spiritual, cultural, institutional and territorial factors), which makes it impossible to introduce systematic monitoring and complex analysis for these processes.

Thus, the study solves the following issues:

- forming a system of indicators to assess the conditions affecting population migration activity and their classification into stimulators (their increased values lead to "pushing" migrants out of the region) and de-stimulators (their increased values ensure migration "restraining");

- forming a methodological approach to assessing the degree of indicators' influence - factors and their groups, the calculation of integral indexes of the conditions affecting population migration activity;

- guaranteeing the analysis and forecasting of population migration activity under the influence of a system of indicators (factors).

\section{Methodology}

The methodology of assessing the conditions affecting population migration activity in the region (based on calculating an integral index) includes six stages: normalization of indicators, determination of indicators' weights in a group, evaluation of weighted multi-dimensional indexes of indicators' groups, determination of weights of indicators' groups, estimation of calculation reliability and an integral index construction.

\section{Stage 1. Normalization of indicators}

The normalization is carried out by formula (1) for the indicators-stimulators and by formula (2) for the indicators-de-stimulators:

$$
\begin{aligned}
z^{s}{ }_{i j} & =\frac{x_{i j}}{x_{\max j}}, \\
z^{d}{ }_{i j} & =\frac{x_{\min j}}{x_{i j}},
\end{aligned}
$$

in which $z_{i j}^{s}$ is standardized values of $i$-stimulator in $j$-time interval $(i=\overline{1, n} ; j=\overline{1, m})$;

$z^{d}{ }_{i j}$ is standardized values of $i$-de-stimulator in $j$ time interval $(i=\overline{1, n} ; j=\overline{1, m})$;

$x_{i j}$ is output values of the indicators $(i=\overline{1, n}$; $j=\overline{1, m})$; $x_{\min j}, x_{\max j}$ are minimum and maximum values of $i$ indicator in $j$-time interval $(i=\overline{1, n} ; j=\overline{1, m})$.

Under the results of normalization of indicatorsstimulators and indicators-de-stimulators, normalized series of indicators $\left(z_{i j}\right)$ are formed for each group.

Stage 2. Determination of indicators' weights in a group

The indicators' weights are determined by the method of constructing a correlation matrix (paired correlation comparisons) for each group of indicators separately, herewith they are constant values during the study period (formulas 3 and 4).

$$
\begin{aligned}
& \left|\begin{array}{l}
r_{11} r_{12} r_{13} r_{14} \ldots r_{1 n} \\
r_{21} r_{22} r_{23} r_{24} \ldots r_{2 n} \\
\cdots \ldots \ldots \ldots \ldots . \ldots . \ldots . \ldots . \ldots \\
r_{n 1} r_{n 2} r_{n 3} r_{n 4} \ldots r_{n n}
\end{array}\right|, \\
& a_{t}=\left(\begin{array}{l}
r_{11}+r_{12}+r_{13}+r_{14}+\ldots .+r_{1 n} \\
r_{21}+r_{22}+r_{23}+r_{24}+\ldots+r_{2 n} \\
r_{31}+r_{32}+r_{33}+r_{34}+\ldots+r_{3 n} \\
\ldots \ldots \ldots \ldots \ldots \ldots \ldots \ldots \ldots \ldots \ldots \ldots \ldots \ldots \ldots \ldots \ldots \ldots \ldots \ldots \ldots \ldots \ldots \ldots \ldots \ldots \ldots \ldots \ldots \ldots \ldots \\
r_{n 1}+r_{n 2}+r_{n 3}+r_{n 4}+\ldots .+r_{n n}
\end{array}\right)=\left(\begin{array}{c}
a_{1} \\
a_{2} \\
a_{3} \\
\ldots \\
a_{n}
\end{array}\right), \\
& a_{t}=\sum a_{n}
\end{aligned}
$$

in which $r_{n i}$ is coefficients of the paired correlation of $n$-indicators in $k$-group;

$a_{n}$ is a sum of the elements of $n$-row of the correlation matrix.

$$
w_{k i}=\frac{a_{t}}{\sum_{n=1}^{i} r_{n i}}, \quad w_{k i}>0, \quad \sum w_{k i}=1
$$

where $w_{k i}$ is the value of the weight of $i$-indicator in $k$-group $(i=\overline{1, n} ; k=\overline{1,5})$.

Stage 3. Evaluation of weighted multidimensional indexes of indicators' groups

The weighted indexes for each group of indicators are calculated by formula (5).

$$
I_{k j}=\sum_{j=1}^{m} w_{k} \times z_{i j}
$$

in which $I_{k j}$ is a weighted index of $k$-group of indicators in $j$-time interval $(k=\overline{1,5} ; j=\overline{1, m})$.

Stage 4. Determination of weights of indicators' groups

The weights of indicators' groups, as well as the weights of indicators in a group (See stage 2), are set made by using the method of a correlation matrix construction, whose elements are paired correlation comparisons of the calculated weighted indexes of the indicator' groups (formula 6). 


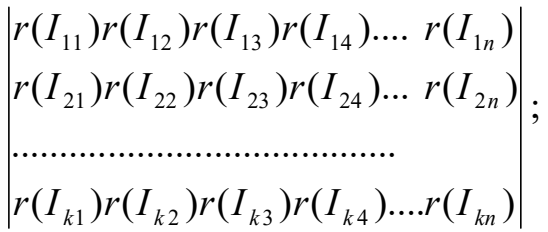

$$
\begin{aligned}
& w_{k}>0, \quad \sum w_{k}=1
\end{aligned}
$$

in which $r\left(I_{k n}\right)$ is a coefficient of the correlation of the weighted index of $k$-indicator group; $w_{k}$ is the value of the weight of $k$-indicator group $(k=\overline{1,5})$.

Stage 5. Estimation of calculation reliability

The conclusion on the relationship reliability is drawn using $t$-test (Student's criterion). The calculated values of the criterion are compared with the table values, where $\alpha$ is a selected significance level $n-1$ degrees of freedom $(d f)$.

with

If the calculated values of statistics at the given significance level $(p<0.050 ; p<0.010 ; p<0.001)$ and degrees of freedom $(d f=12)$ exceed the table value $(t=2.179 ; t=3.055 ; t=4.318)$, the obtained results are reliable.

Stage 6. Integral index construction

The integral index of the conditions affecting population migration activity is calculated by formula (7):

$$
Y_{j}=\sum_{j=1}^{m} w_{k} \times I_{k j}
$$

in which $Y_{j}$ is the value of the integral index of the conditions affecting population migration activity in $j$-time interval $(j=\overline{1, m})$.

\section{Results}

In order to assess the conditions affecting population migration activity, 30 indicators classified into five groups are selected by the method of an integral index construction (Table 1):

(1) demographic stability and public health status;

(2) education coverage;

(3) labour market and employment conditions;

(4) standard of living;

(5) economic development of the country.
Table 1. Indicators for assessing the conditions affecting

\begin{tabular}{|c|c|}
\hline Indicators & $\begin{array}{l}\text { Impact on } \\
\text { migration }^{\mathrm{a}}\end{array}$ \\
\hline \multicolumn{2}{|c|}{ Group 1: Demographic stability and public health status } \\
\hline General birth rate per 1,000 population $\left(x_{l .1}\right)$ & Stimulator \\
\hline $\begin{array}{l}\text { General mortality rate per } 1,000 \text { population } \\
\left(x_{I .2}\right)\end{array}$ & De-stimulator \\
\hline Average life expectancy at birth $\left(x_{1.3}\right)$ & Stimulator \\
\hline Marriage rate per 1,000 population $\left(x_{1.4}\right)$ & De-stimulator \\
\hline Morbidity rate per 100,000 population $\left(x_{1.5}\right)$ & Stimulator \\
\hline $\begin{array}{l}\text { Percentage of rural population } \\
\left(x_{1.6}\right)\end{array}$ & Stimulator \\
\hline \multicolumn{2}{|l|}{ Group 2: Education coverage } \\
\hline $\begin{array}{l}\text { Number of vocational education students } \\
\text { per } 10,000 \text { population }\left(x_{2.1}\right)\end{array}$ & De-stimulator \\
\hline $\begin{array}{l}\text { Number of higher education students per } \\
10,000 \text { population }\left(x_{2.2}\right)\end{array}$ & De-stimulator \\
\hline $\begin{array}{l}\text { Percentage of graduates from secondary } \\
\text { education of total number of school students } \\
\left(x_{2.3}\right)\end{array}$ & Stimulator \\
\hline \multicolumn{2}{|c|}{ Group 3: Labour market and employment conditions } \\
\hline $\begin{array}{l}\text { Unemployment rate for the population aged } \\
15-70\left(x_{3.1}\right)\end{array}$ & Stimulator \\
\hline Worker inflow rate $\left(x_{3.2}\right)$ & De-stimulator \\
\hline Worker outflow rat & Stimulator \\
\hline $\begin{array}{l}\text { Employment rate for } \\
70\left(x_{3.4}\right)\end{array}$ & De-stimulator \\
\hline $\begin{array}{l}\text { Rate of invo } \\
\left(x_{3.5}\right)\end{array}$ & Stimulator \\
\hline $\begin{array}{l}\text { Percentage of emp } \\
\text { hazardous conditio }\end{array}$ & Stimulator \\
\hline $\begin{array}{l}\text { Averag } \\
\text { employ }\end{array}$ & De-stimulator \\
\hline $\begin{array}{l}\text { Occu } \\
\text { incid }\end{array}$ & Stimulator \\
\hline of informal sector employment $\left(x_{3.9}\right)$ & Stimulator \\
\hline \multicolumn{2}{|l|}{ Group 4: Standard of living } \\
\hline Household real income per capita $\left(x_{4.1}\right)$ & De-stimulator \\
\hline Cons & Stimulator \\
\hline $\begin{array}{l}\text { Population expenditure-to-income growth } \\
\text { rate ratio }\left(x_{4.3}\right)\end{array}$ & Stimulator \\
\hline er capita & De-stimulator \\
\hline $\begin{array}{l}\text { Household food expenditure share of total } \\
\text { spending }\left(x_{4.5}\right)\end{array}$ & Stimulator \\
\hline Decile coefficient of inco & Sti \\
\hline $\begin{array}{l}\text { Average housing (utility) subsidies per } \\
\text { family }\left(x_{4.7}\right)\end{array}$ & De-stimulator \\
\hline \multicolumn{2}{|c|}{ Group 5: Economic development of the country } \\
\hline Foreign direct investments per capita $\left(x_{5.1}\right)$ & De-stimulator \\
\hline Capital investments per capita $\left(x_{5.2}\right)$ & De-stimulator \\
\hline Gross value added pe & mulator \\
\hline $\begin{array}{l}\text { Number of small-sized enterprises per } \\
10,000 \text { population }\left(x_{5.4}\right)\end{array}$ & De-stimulator \\
\hline $\begin{array}{l}\text { Share of enterprises that introduced product } \\
\text { or process innovations }\left(x_{5.5}\right)\end{array}$ & $D e-$ \\
\hline
\end{tabular}
population migration activity

Notes: ${ }^{a}$ Indicators' impact on migration is defined based on the expert opinion.

${ }^{b}$ The decile coefficient is the indicator that measures the disparity of income distributions between the poorest $10 \%$ of the population and that of the richest $10 \%$. 
Taking into account the results of the normalization of the factors (indicators) affecting population migration activity in Ukraine (given in Annex A) and formulas (3) and (4), the weights of each indicator within the respective groups are determined (Table 2). It is found that the following factors have the highest significance levels (weights in per cent):

- in group "demographic stability and public health status": average life expectancy at birth $(20.19 \%)$, the percentage of rural population (20.0\%) and general mortality rate (19.71\%);

- in group "education coverage": the number of vocational education students per 10,000 population (38.24\%);

- in group "labour market and employment
Table 3. Weighted multi-dimensional indexes for indicators' groups $\left(I_{k j}\right)$

\begin{tabular}{|c|c|c|c|c|c|}
\hline & $I_{1 j}$ & $I_{2 i}$ & $I_{3 i}$ & $I_{4 i}$ & $I_{5 i}$ \\
\hline 2005 & 0.9034 & 0.3877 & 0.8549 & 0.9414 & 0.8103 \\
\hline 2006 & 0.9044 & 0.3855 & 0.8139 & 0.8637 & 0.6782 \\
\hline 2007 & 0.8917 & 0.3913 & 0.7750 & 0.7410 & 0.5490 \\
\hline 2008 & 0.9276 & 0.3795 & 0.7808 & 0.7436 & 0.5227 \\
\hline 2009 & 0.9433 & 0.3618 & 0.8726 & 0.7703 & 0.6775 \\
\hline 2010 & 0.9484 & 0.3556 & 0.8205 & 0.7296 & 0.6003 \\
\hline 2011 & 0.9400 & 0.2335 & 0.7788 & 0.6969 & 0.5303 \\
\hline 2012 & 0.9678 & 0.3355 & 0.7590 & 0.6671 & 0.5045 \\
\hline 2013 & 0.9511 & 0.8167 & 0.7506 & 0.6693 & 0.4975 \\
\hline 2014 & 0.9308 & 0.6070 & 0.8115 & 0.7315 & 0.7610 \\
\hline 2015 & 0.9128 & 0.5995 & 0.8308 & 0.7883 & 0.7665 \\
\hline 2016 & 0.9626 & 0.6000 & 0.7913 & 0.7398 & 0.7485 \\
\hline 2017 & 0.9277 & 0.6070 & 0.7769 & 0.7369 & 0.6680 \\
\hline
\end{tabular}

Note: Calculated based on Table 2 and formula (5)

Table 2. Indicators' weights in a group $\left(w_{k i}\right), \%$

\begin{tabular}{|c|c|c|c|c|c|c|c|c|c|}
\hline $\boldsymbol{x}_{1 i}$ & $w_{1 i}$ & $\boldsymbol{x}_{\mathbf{2 i}}$ & $w_{2 i}$ & $\boldsymbol{x}_{3 i}$ & $w_{3 i}$ & $\boldsymbol{x}_{4 i}$ & $w_{4 i}$ & $\boldsymbol{x}_{5 i}$ & $w_{5 i}$ \\
\hline $\mathrm{x}_{1.1}$ & 10.91 & $\mathrm{x}_{2.1}$ & 38.24 & $\mathrm{x}_{3.1}$ & 13.79 & $\mathrm{x}_{4.1}$ & 16.48 & $\mathrm{x}_{5.1}$ & 13.21 \\
\hline $\mathrm{x}_{1.2}$ & 19.71 & $\mathrm{x}_{2.2}$ & 27.30 & $\mathrm{x}_{3.2}$ & 12.39 & $\mathrm{x}_{4.2}$ & 10.41 & $\mathrm{x}_{5.2}$ & 24.15 \\
\hline $\mathrm{x}_{1.3}$ & 20.19 & $\mathrm{x}_{2.3}$ & 34.45 & $\mathrm{x}_{3.3}$ & 8.96 & $\mathrm{x}_{4.3}$ & 10.63 & $\mathrm{x}_{5.3}$ & 24.75 \\
\hline $\mathrm{x}_{1.4}$ & 13.95 & & & $\mathrm{x}_{3.4}$ & 11.55 & $\mathrm{x}_{4.4}$ & 17.91 & $\mathrm{x}_{5.4}$ & 21.50 \\
\hline $\mathrm{x}_{1.5}$ & 15.25 & & & $\mathrm{x}_{3.5}$ & 7.69 & $\mathrm{x}_{4.5}$ & 15.72 & $\mathrm{x}_{5.5}$ & 16.39 \\
\hline $\mathrm{x}_{1.6}$ & 20.00 & & & $\mathrm{x}_{3.6}$ & 11.00 & $\mathrm{x}_{4.6}$ & 11.21 & & \\
\hline & & & & $\mathrm{x}_{3.7}$ & 9.55 & $\mathrm{x}_{4.7}$ & 17.63 & & \\
\hline & & & & $\mathrm{x}_{3.8}$ & 13.10 & & & & \\
\hline & & & & $\mathrm{x}_{3.9}$ & 11.97 & & & & \\
\hline & 100.00 & & 100.00 & & 100.00 & & 100.00 & & 100.00 \\
\hline
\end{tabular}

Note: Calculated based on Annex A, formulas (3) and (4)

conditions": the unemployment rate for the population aged 15-70 (13.79\%), occupational injury rate $(13.10 \%)$ and worker inflow rate $(12.39 \%)$;

- in group "standard of living": housing per capita in sq. m. (17.91\%) and average housing (utility) subsidies per family $(17.63 \%)$;

- -in group "economic development of the country": gross value added per capita (24.75\%) and capital investments per capita (24.15\%).

The weighted indexes for each group of indicators (Table 3) are calculated and based on the linear combination of the normalized indicators' values, and their weights in the group. The indexes' values demonstrate the level of push factors for population external migration. In 2005, the biggest pushing effect was caused by the group of factors "standard of living" (index value is 0.9414), while the group "education coverage" had the smallest effect (0.3877).
During the period of the world economic crisis in 2008-2009, the demographic component considerably contributed to population "pushing", specifically out of the Eastern European region, including Ukraine. The discrepancy between the demand and supply in the labour market and the needs that were not satisfied caused increased migration namely among rural population, the share of which was prevailing. The economic development of Ukraine had an insignificant impact on "pushing" the population in 2011-2013, since the main migration activity stimulators during that period included a low wage and the deficit of well-paid jobs. Since 2013, certain segments of population began being dissatisfied with education services, which resulted in pushing, namely Ukrainian youth, to study abroad. The value of weighted multi-dimensional index for group "education coverage" increased almost twice.

The beginning of a military conflict in the East of the country and the annexation of the Crimea caused increased migration of the Ukrainian population; in particular, migration processes among the local population on the frontline territories intensified. In 2016-2017, the value of the weighted index of the group "labour market and employment conditions" 
was between 0.777 and 0.791 , whereas "economic development of the country" was 0.668 .

To define the weights of each indicator's group, paired correlation comparisons of the weighted group indexes, based on the created matrix (Table 4), are accomplished. The reliability of the calculations in the correlation matrix of the indicators' groups is assessed using $t$-test $\left(t\right.$-statistic $\left.>t_{\text {table }}\right)$ at $d f=12$.

Table 4. Paired correlation comparisons of the indicators' groups and calculated values of t-test

\begin{tabular}{|c|c|c|c|c|c|c|}
\hline $\boldsymbol{r}_{\boldsymbol{i} \boldsymbol{j}}$ & $\boldsymbol{r}_{\boldsymbol{1}}$ & $\boldsymbol{r}_{2}$ & $\boldsymbol{r}_{\boldsymbol{3}}$ & $\boldsymbol{r}_{4}$ & $\boldsymbol{r}_{5}$ & $\boldsymbol{w}_{\boldsymbol{k}}, \boldsymbol{\%}$ \\
\hline$r_{1}$ & 1.0000 & & & & & 18.0177 \\
\hline$r_{2}$ & 0.1262 & 1.0000 & & & & 13.3645 \\
\hline$t$-test & $\mathbf{1 0 . 1 9 7 3}$ & & & & & \\
\hline$r_{3}$ & 0.2946 & 0.2438 & 1.0000 & & & 22.1824 \\
\hline$t_{\text {-test }}$ & $\mathbf{1 0 . 7 8 8 6}$ & $\mathbf{7 . 2 3 6 5}$ & & & & \\
\hline$r_{4}$ & 0.6657 & 0.1940 & 0.7005 & 1.0000 & & 24.4356 \\
\hline$t$-test & $\mathbf{8 . 0 3 7 9}$ & $\mathbf{5 . 8 0 6 7}$ & $\mathbf{1 . 9 7 4 0}$ & & & \\
\hline$r_{5}$ & 0.3104 & 0.2138 & 0.7120 & 0.6904 & 1.0000 & 21.9998 \\
\hline t-test & $\mathbf{9 . 2 3 5 3}$ & $\mathbf{3 . 1 6 6 1}$ & $\mathbf{4 . 9 6 4 8}$ & $\mathbf{3 . 0 9 8 1}$ & & \\
\hline
\end{tabular}

Note: ${ }^{*} p<0.05$. Calculated based on Table 3, formula (6) and algorithm described in Stage 5
The coefficients of significance serve as necessary criteria due to which the integral indexes of the conditions affecting population migration activity in Ukraine in 2005-2017 are calculated (Figure 1).

The obtained results allowed the authors to define several peak stages when the migration activity environment in Ukraine was the most "aggressive" in the context of "pushing" the population abroad. They were 2005, 2009 and 2015 years. The impact of migration factors was growing to a great extent from 2013 to 2015 due to the deterioration of the country's economic state, the decreased level of social security and also political instability and foreign military aggression against Ukraine.

Although in 2016-2017 the impact of migration factors tended to be lower, the level of their influence still remained high, which led to the growth of foreign, especially labour, migration from Ukraine.

The value of the integral index fluctuates within the range from 0 to 1 . The index growth affirms enabling conditions affecting population migration activity for "pushing" and vice versa. The gradation of the integral index is accomplished based on Harrington utility function (Table 5).

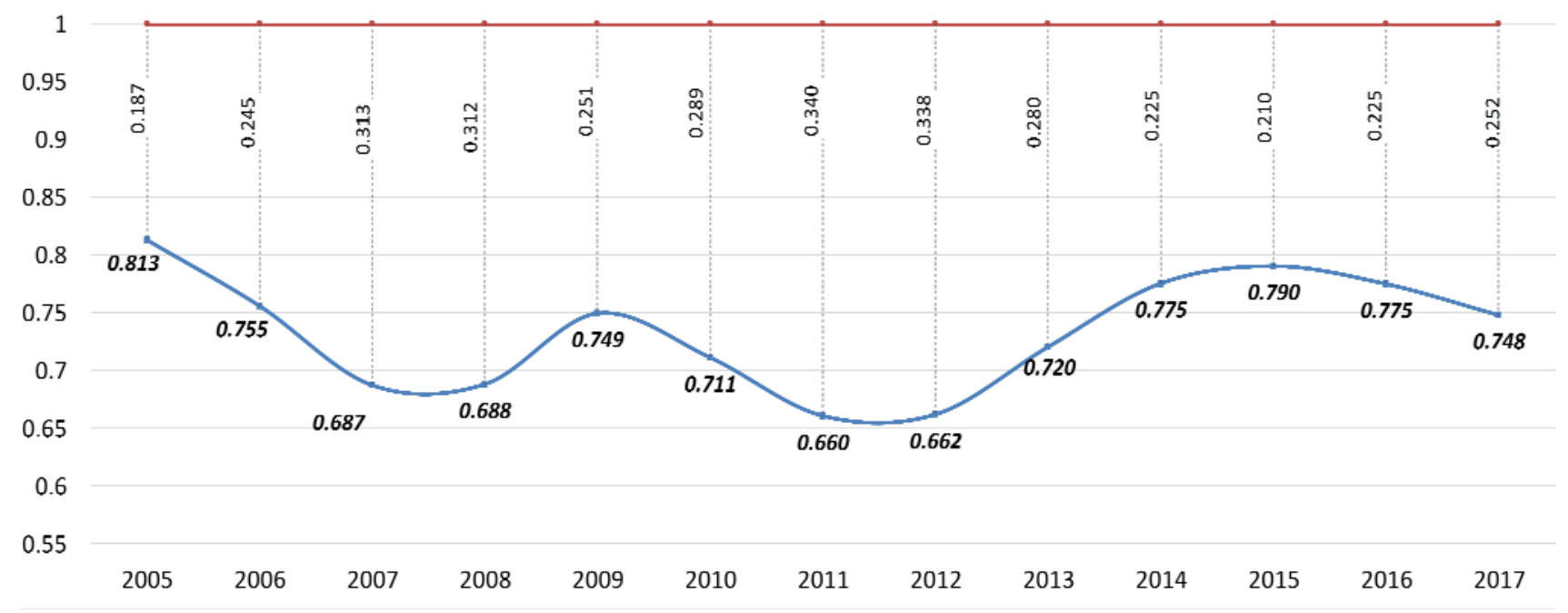

Figure 1. Integral index of the conditions affecting population migration activity in Ukraine $\left(Y_{j}\right), 2005-2017$

Note: Gaps are presented with absolute distinction between the integral index values and the top critical level of "pushing" the migrants out of the country. Constructed by formula (7)

The distribution of significance by factor groups allows the authors to claim that the factors of the group "standard of living" define population migration activity in Ukraine to the greatest extent. The significance of this group is $24.44 \%$. The values of the significance level of the group "labour market and employment conditions" (22.18\%) and the group "economic development of the country" are also high $(22.00 \%)$. The factors of demographic stability, public health status and education coverage have a slightly lower impact on population migration activity.
The value of the integral index of the conditions affecting population foreign migration activity in Ukraine in 2005-2017 was within the limits of 0.660.81 , which shows an enabling environment for "pushing" population abroad. Based on the results of integral assessment, it is found that the conditions were favourable for "pushing" the population during all the researched period, and in some years, the index was maximally close to the top critical value. 
Table 5. Gradation of the integral index of the conditions affecting population migration activity (the level of "pushing”).

\begin{tabular}{|c|l|}
\hline Value & Specificity of conditions \\
\hline $1.00-0.81$ & Maximum enabling \\
\hline $0.80-0.64$ & Enabling \\
\hline $0.63-0.38$ & Enabling enough \\
\hline $0.37-0.21$ & Low-level enabling \\
\hline $0.20-0.00$ & Not enabling \\
\hline
\end{tabular}

To prove the reliability of the obtained data, especially on a real impact of the considered conditions on the volume of population migration in Ukraine, the correlation analysis is used (Table 6). In particular, the dependence between the integral index of the conditions affecting population migration activity and the dynamics of people's going abroad, taken as the rate of foreign migration activity $\left(M_{j}\right)$, is assessed.

The correlation between the integral indexes of the conditions affecting population migration activity and the rate of foreign migration activity in 20112017 was 0.79 , which is a high value and proves a close relationship between the analysed variables. Therefore, increased migration is highly expected as

\section{Conclusion}

International migration is an important element of modern demographic policy, but given its changing nature, it remains the most unpredictable among other demographic characteristics. In this regard, the creation of a system that estimates population migration activity to solve its problems is topical for Ukraine, which is one of the largest migrant donor countries for the EU countries.

For modelling the conditions affecting population migration activity, 30 indicators classified into five groups are selected by the method of an integral index construction: demographic stability and public health status; education coverage; labour market and employment conditions; standard of living; economic development of the country/region.

It is proved that population migration activity is primarily determined by the demographic situation, life expectancy, public health status, upbringing of the young generation, the atmosphere in the family and so on. In Ukraine, there is a tendency of a decline in birth rate and an increase in mortality (especially those of working age). The prevalence of the last indicator over the former is a threat to demographic reproduction, and it can lead to a

Table 6. Relationship between the conditions affecting population migration activity in Ukraine and the rate of foreign migration activity: correlation analysis results

\begin{tabular}{|c|c|c|c|c|c|c|c|}
\hline & 2011 & 2012 & 2013 & 2014 & 2015 & 2016 & 2017 \\
\hline People's going abroad, thous. & 19703.3 & 21064.4 & 23264.6 & 22636.5 & 26120.8 & 24345.5 & 26180.8 \\
\hline $\begin{array}{c}\text { Rate of foreign migration } \\
\text { activity }\left(M_{i}\right)^{* *}\end{array}$ & 0.430 & 0.462 & 0.511 & 0.498 & 0.609 & 0.569 & 0.615 \\
\hline & \multicolumn{2}{|c|}{$\begin{array}{l}\text { Correlation } \\
\text { coefficient }\end{array}$} & \multicolumn{2}{|c|}{$\begin{array}{c}\text { Coefficient of determination } \\
\text { (R-squared) }\end{array}$} & \multicolumn{2}{|c|}{$t$-test } & p-value \\
\hline$Y_{j}-M_{j}$ & \multicolumn{2}{|c|}{0.792948} & \multicolumn{2}{|c|}{0.628766} & \multicolumn{2}{|c|}{2.91009} & 0.033396 \\
\hline$I_{1 j}-M_{j}$ & \multicolumn{2}{|c|}{-0.473892} & \multicolumn{2}{|c|}{0.224574} & \multicolumn{2}{|c|}{-1.20336} & 0.282701 \\
\hline$I_{2 j}-M_{j}$ & \multicolumn{2}{|c|}{0.593578} & \multicolumn{2}{|c|}{0.352335} & \multicolumn{2}{|c|}{1.64925} & 0.160009 \\
\hline$I_{3 j}-M_{j}$ & \multicolumn{2}{|c|}{0.439848} & \multicolumn{2}{|c|}{0.193466} & \multicolumn{2}{|c|}{1.09516} & 0.323375 \\
\hline$I_{4 j}-M_{j}$ & \multicolumn{2}{|c|}{0.750620} & \multicolumn{2}{|c|}{0.563431} & \multicolumn{2}{|c|}{2.54026} & 0.051877 \\
\hline$I_{5 j}-M_{j}$ & \multicolumn{2}{|c|}{0.662684} & \multicolumn{2}{|c|}{0.439150} & \multicolumn{2}{|c|}{1.97865} & 0.104759 \\
\hline
\end{tabular}

Notes: *Ukrainian citizens' going abroad (to the countries by frequency of visits: Australia, Belarus, United Kingdom, Greece, Egypt, Israel, Spain, Italy, Moldova, Germany, UAE, Poland, Russia, Slovakia, Turkey, Hungary, Czech Republic). The purpose of visits: business, tourism, private, service.

${ }^{* *}$ Ratio of the number of visits abroad to total number of population.

the factors causing "pushing" the population abroad grow.

A close relationship between the foreign migration activity in Ukraine and the groups of factors affecting migration is established, especially the groups: standard of living (correlation is 0.75), economic development of Ukraine (0.66) and education coverage (0.59).

The presented results are quite reliable, which is proved by the values of the obtained coefficients of determination, $t$-test and significance level. catastrophic population decline. Against this background, the increasing migration activity has negative consequences for the demographic situation in Ukraine and significantly reduces the level of demographic security. On the other hand, in terms of current global trends, the nation's aging and depopulation are the problems of many countries, which compensate for the low birth rate by immigration (substitution effect).

The place of work, guaranteed employment, the spread of part-time and informal employment, 
various aspects of labour movement, working conditions and pay, of course, create a socioeconomic basis of the conditions affecting population migration activity. Such indicators as the unemployment rate for population aged 15-70 years, the worker outflow rate, the level of involuntary underemployment, the share of employees working in hazardous conditions, as well as the occupational injury rate, are important qualitative characteristics of the conditions affecting population migration activity. They testify to an increased pushing effect on Ukrainian labour migrants, causing catastrophic shortage of human resources in the production sector.

The deterioration of the economic situation in the country or region, and consequently, the decline in guarantees of stable employment and decent living standards, are pushing the citizens to try to find higher-paid jobs, and to get education (often tuition free) in other countries. Accordingly, a decrease in the household real income, active inflationary processes, exceeding population expenditure growth over the income growth, limited financial capacity of citizens in terms of savings and investment (due to the high level of the household food expenditure share) lead to more pro-migration attitude. The increase in the consumer price index, the population expenditure-to-income growth rate ratio, as well as the household food expenditure share of total spending reflect a high level of enabling migration conditions for "pushing" population abroad. Conversely, rising incomes increase the demand for job vacancies and, thus, impede labour migration.

The economic situation in Ukraine is an important reason for the population labour emigration, whose further intensification threatens the economic development of Ukraine's regions and the national security as a whole. In order to overcome the fatal tendency when labour emigration accelerates the development of the economy of foreign countries, it is necessary to provide attractive conditions for foreign investors to enter the economy of the country and its regions, an increase of capital investments, increase of gross value added, growth activity for small business entities and an increase of the share of innovatively active enterprises. Therefore, the improvement of the values regarding these and other major macroeconomic parameters will serve as a factor to impede population external migration.

The approbation of the authors' methodological approach allows assessing the conditions affecting population migration activity with the further forecasting of relevant effects on the volume and rate of population migration in the regions of Eastern Europe, as well as migration balances within interregional (interstate) migration systems. The results allow authors to identify key quantitative factors influencing the activation or restraint of population migration activity from Ukraine to European countries, and serve as a conceptual basis for regulating the trends and rates of population migration growth (restraint) in the region.

\section{Acknowledege}

The research has been conducted within the framework of Applied Research "Migration Activity of the Population of the Carpathian Region" (M. Dolishniy Institute of Regional Research of National Academy of Sciences of Ukraine, Reg. No. 0119U002010, period: 2019-2021).

\section{References}

[1]. Becker, S. O. \& Ferrara, A. (2019). Consequences of forced migration: A survey of recent findings. Labour Economics, 59, 1-16. https://doi.org/10.1016/j.labeco.2019.02.007.

[2]. Fischer, L. B. \& Pfaffermayr, M. (2018). The more the merrier? Migration and convergence among European regions. Regional Science and Urban Economics, 72, 103-114. https://doi.org/10.1016/j.regsciurbeco.2017.04.007.

[3]. Fisher, M. H. (2013). Migration: A world history. Oxford University Press.

[4]. Hear, N. V., Bakewell, O. \& Long, K. (2017). Pushpull plus: reconsidering the drivers of migration. Journal of Ethnic and Migration Studies, 44(1), 1-18. https://doi.org/10.1080/1369183X.2017.1384135.

[5]. Imran, A. (2019). The determinants of international migration: Unbundling the role of economic, political, and social institutions. World Economy, 1(1), 5-15. https://doi.org/10.1111/twec.12889.

[6]. Katsarski, N. (2019). Factors determining migration of the population International Journal of Knowledge Management 30(6), 1729-1733.

[7]. Arthur, P. L., Ensor, J., van Faassen, M., Hoekstra, R., \& Peters, N. (2018). Migrating People, Migrating Data: Digital Approaches to Migrant Heritage. Journal of the Japanese Association for Digital Humanities, 3(1), 98-113.

https://doi.org/10.17928/jjadh.3.1_98.

[8]. Mahmoud, T. O. \& Trebesch, C. (2010). The economics of human trafficking and labour migration: Micro-evidence from Eastern Europe. Journal of Comparative Economics, 38(2), 173-188. https://doi.org/10.1016/j.jce.2010.02.001.

[9]. Pitkänen, P., Hayakawa, T., Schmidt, K., Aksakal, M. \& Rajan, S. I. (2019). Temporary Migration, Transformation and Development: Evidence from Europe and Asia. London: Routledge. https://doi.org/10.4324/9780429244346.

[10]. Public Union "Economic Discussion Club" (2019). Analytics. Retrieved from: http://edclub.com.ua/analityka. [accessed: 05 September 2019].

[11]. Segal, U. A. (2019). Globalization, migration, and ethnicity. Public Health, 172, 135-142. https://doi.org/10.1016/j.puhe.2019.04.011.

[12]. State Statistics Service of Ukraine (2019). Official web-site. Retrieved from:http://www.ukrstat.gov.ua [accessed: 10 January 2020]. 
[13]. Vollmer, B., \& Malynovska, O. (2016). Ukrainian migration research before and since 1991. In Ukrainian Migration to the European Union (pp. 17-33). Springer, Cham. https://doi.org/10.1007/9783-319-41776-9 2.
[14]. Zimmermann, K. F. (1996). European Migration: Push and Pull. International Regional Science Review, 19(1-2), 95-128.

https://doi.org/10.1177/016001769601900211.

Annex A. Normalized values of factors (indicators) affecting population migration activity in Ukraine, $z_{i j}$

\begin{tabular}{|c|c|c|c|c|c|c|c|c|c|c|c|c|c|}
\hline $\mathbf{z}_{\mathrm{ij}}$ & 005 & 006 & 07 & 2008 & 2009 & 2010 & 2011 & 2012 & 2013 & 2014 & 015 & 016 & 017 \\
\hline \multicolumn{14}{|c|}{ 1. Demographic stability and public health status } \\
\hline .1 & 0.7895 & 8596 & 8947 & 9649 & 9737 & 9474 & 9649 & .0000 & 9737 & 9474 & 0.9386 & 9035 & 8246 \\
\hline 1.2 & 0.8253 & 0.8457 & 8354 & 8405 & 8954 & 9013 & 0.9448 & 0.9448 & 9384 & 9320 & 9195 & .0000 & .9448 \\
\hline $\mathbf{x}_{1.3}$ & 9461 & 9482 & 485 & 9626 & 0626 & 9786 & 9867 & 9885 & 9915 & 9915 & 9917 & 958 & 0000 \\
\hline$x_{1.4}$ & 0.8310 & 0.7763 & 0.6556 & 0.8429 & 0.8551 & 0.8806 & 0.7564 & 0.9672 & .8806 & .8551 & 0.7564 & .0000 & 9077 \\
\hline 1.5 & 0.9687 & 0.9554 & 781 & 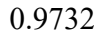 & 0.994 & 000 & 4 & 78 & 57 & 8 & 670 & 891 & 8687 \\
\hline $\mathbf{x}_{1.6}$ & 1.0000 & 0.9931 & 871 & 9820 & & 0.9729 & & 0.9675 & 9639 & 608 & 0.9564 & 0.9544 & 9531 \\
\hline \multicolumn{14}{|c|}{ 2. Education coverage } \\
\hline 2.1 & 0.0556 & 0.0583 & 0611 & 0.0639 & 0.0654 & 0.0682 & 80 & 0.0 & & & 014 & 552 & 0000 \\
\hline $\mathbf{x}_{2.2}$ & 0.0901 & 0.0871 & 58 & 8 & 919 & 956 & 1020 & 092 & 000 & 23 & 7 & 94 & 433 \\
\hline $\mathrm{x}_{2.3}$ & 0.9921 & 0.9852 & 1.0000 & 0.9619 & 0.9047 & 0.8806 & 0.5210 & 0.8105 & 0.7521 & 0.6838 & 0.6296 & .5706 & .5383 \\
\hline \multicolumn{14}{|c|}{ 3. Labour market and employment conditions } \\
\hline $\mathbf{X}_{3.1}$ & 0.7579 & 0.7158 & 6737 & 0.6737 & 0.9263 & 0.8526 & 0.8316 & 0.7895 & 0.7579 & 39 & 79 & 789 & 000 \\
\hline $\mathbf{x}_{3.2}$ & 0.8212 & 0.7895 & 0.7576 & 0.7951 & 1.0000 & 0.8893 & 0.7867 & 0.8523 & 0.8364 & 0.9868 & 0.9375 & 8621 & 0.7377 \\
\hline $\mathbf{x}_{3.3}$ & 0.8902 & 0.9055 & 0.9360 & 1.0000 & 0.8750 & 0.8567 & 0.9421 & 0.9238 & 29 & 9238 & 0.9207 & 8902 & 9695 \\
\hline $\mathbf{x}_{3.4}$ & 0.9723 & 0.9689 & 9557 & 0.9460 & 0.9723 & 0.9606 & 0.9492 & 0.9 & 19 & 0.9912 & 0.9894 & .9964 & 0000 \\
\hline $\mathrm{x}_{3.5}$ & 0.3814 & 0.3093 & 0.2268 & 0.5464 & 1.0000 & 0.7010 & 0.4433 & 0.3608 & 0.4072 & 0.5103 & 0.4742 & 3041 & 3608 \\
\hline $\mathbf{x}_{3.6}$ & 0.9322 & 0.9288 & 9288 & 0.9390 & $0.94 \angle 4$ & 21 & 97 & 864 & 000 & 031 & 797 & 322 & 9627 \\
\hline $\mathbf{x}_{3.7}$ & 1.0000 & 0.7630 & 879 & 0.4 & 0.6 & 74 & 2 & 3 & 30 & 72 & 0 & 754 & 870 \\
\hline $\mathbf{x}_{3.8}$ & 1.0000 & 0.9444 & 0.8889 & 0.7778 & 0.6667 & 0.6667 & 0 & 6 & 0 & 3 & 3 & 3 & 3889 \\
\hline $\mathbf{x}_{3.9}$ & 0.8206 & 0.8511 & 8511 & 0.8321 & 0.8435 & 0.8740 & 0.8817 & 0.8740 & 0.9008 & 0.9580 & 1.0000 & 275 & 0.8740 \\
\hline \multicolumn{14}{|c|}{ 4. Standard of living } \\
\hline $\mathbf{x}_{4.1}$ & 1.0000 & 0.8030 & 0.6162 & 745 & 0.6698 & 304 & 0.455 & 7 & 96 & 4 & 37 & 14 & 930 \\
\hline$x_{4.2}$ & 0.7697 & 0.7788 & 0.8137 & 0.8535 & 0.7837 & 0.7613 & 0.7299 & 0.6964 & 0.7013 & 0.8716 & 1.0000 & 0.7844 & 0.7934 \\
\hline $\mathbf{x}_{4.3}$ & 0.88 & 0.96 & 0.9600 & .9574 & 37 & 2 & 9 & 5 & 97 & 00 & 54 & 27 & 370 \\
\hline $\mathbf{x}_{4.4}$ & 1.0000 & 0.9910 & 0.9778 & 0.9649 & 0.9565 & 0.9442 & 0.9362 & 0.9283 & 244 & 0.9735 & 0.9607 & 524 & 0.9442 \\
\hline $\mathbf{x}_{4.5}$ & 1.0000 & 0.9399 & 0.9081 & 0.8640 & 0.8834 & 0.9117 & 0.9064 & 0.8852 & 0.8852 & 0.9170 & 0.9382 & 0.8799 & 0.8463 \\
\hline $\mathbf{x}_{4.6}$ & 0.7955 & 1.0000 & 0.8182 & 0.9318 & 0.8864 & 0.8409 & 0.6818 & 0.6591 & 0.6591 & 0.6364 & 0.6364 & 0.6364 & 0.6818 \\
\hline $\mathbf{x}_{4.7}$ & 1.0000 & 0.6229 & 0.2441 & 0.3497 & 0.4059 & 0.3532 & 0.3021 & 0.3016 & 0.3043 & 0.3077 & 0.3003 & 0.2056 & 0.3509 \\
\hline \multicolumn{14}{|c|}{ 5. Economic development of the country } \\
\hline 5.1 & 0.0547 & 0.0756 & 0.0426 & 0.0384 & 0.0865 & 0.0639 & 0.0573 & 0.0490 & 0.0914 & 1.0000 & 0.1309 & .1175 & 0.1478 \\
\hline $\mathbf{x}_{5.2}$ & 0.7568 & 0.5505 & 0.3637 & 0.3051 & 0.6899 & 0.5619 & 0.4088 & 0.3620 & 0.3963 & 0.6798 & 1.0000 & 0.8857 & 0.7329 \\
\hline $\mathbf{x}_{5.3}$ & 1.0000 & 0.7992 & 0.5912 & 0.4703 & 0.7229 & 0.6137 & 0.5218 & 0.4823 & 0.4548 & 0.6519 & 0.9266 & 0.9015 & 0.7480 \\
\hline 5.4 & 0.9714 & 0.9444 & 0.8947 & 0.9444 & 0.9067 & 0.8718 & 0.8831 & 0.8947 & 0.8293 & 0.8947 & 0.8831 & 1.0000 & 0.8947 \\
\hline & 1.0000 & 0.8200 & 0.7130 & 0.7593 & 0.7664 & 0.7130 & 0.6406 & 0.6029 & 0.6029 & 0.6777 & 0.5395 & 0.4940 & 0.5734 \\
\hline
\end{tabular}

Note: Calculated based on the statistical data from State Statistics Service of Ukraine [12] 